\title{
Intracranial and Intraocular Pressure During Various Degrees of Head-Down Tilt
}

\author{
Karina Marshall-Goebel; Edwin Mulder; Eric Bershad; Charles Laing; Anders Eklund; Jan Malm; Claudia Stern; \\ Jörn Rittweger
}

BACKGROUND: More than half of astronauts develop ophthalmic changes during long-duration spaceflight consistent with an abnormal intraocular and intracranial pressure (IOP, ICP) difference. The aim of our study was to assess IOP and ICP during head-down tilt (HDT) and the additive or attenuating effects of $1 \% \mathrm{CO}_{2}$ and lower body negative pressure (LBNP).

METHODS: In Experiment I, IOP and ICP were measured in nine healthy subjects after $3.5 \mathrm{~h} \mathrm{HDT} \mathrm{in} \mathrm{five} \mathrm{conditions:}-6^{\circ}$, $-12^{\circ}$, and $-18^{\circ}$ HDT, $-12^{\circ}$ with $1 \% \mathrm{CO}_{2}$, and $-12^{\circ}$ with $-20 \mathrm{mmHg}$ LBNP. In Experiment II, IOP was measured in 16 healthy subjects after 5 min tilt at $+12^{\circ}, 0^{\circ},-6^{\circ},-12^{\circ},-18^{\circ}$, and $-24^{\circ}$, with and without $-40 \mathrm{mmHg}$ LBNP.

RESULTS: ICP was only found to increase from supine baseline during $-18^{\circ} \mathrm{HDT}(9.2 \pm 0.9$ and $14.4 \pm 1 \mathrm{mmHg}$, respectively), whereas IOP increased from $15.7 \pm 0.3 \mathrm{mmHg}$ at $0^{\circ}$ to $17.9 \pm 0.4 \mathrm{mmHg}$ during $-12^{\circ} \mathrm{HDT}$ and from $15.3 \pm 0.4 \mathrm{mmHg}$ at $0^{\circ}$ to $18.7 \pm 0.4 \mathrm{mmHg}$ during $-18^{\circ}$ HDT. The addition of $-20 \mathrm{mmHg}$ LBNP or $1 \% \mathrm{CO}_{2}$ had no further effects on ICP or IOP. However, the use of $-40 \mathrm{mmHg}$ LBNP during HDT lowered IOP back to baseline values, except at $-24^{\circ}$ HDT.

DISCUssıon: A small, posterior intraocular-intracranial pressure difference (IOP $>I C P$ ) is maintained during HDT, and a sustained or further decreased difference may lead to structural changes in the eye in real and simulated microgravity.

KEYWORDS: lower body negative pressure, carbon dioxide, visual impairment, translaminar pressure gradient, posture.

Marshall-Goebel K, Mulder E, Bershad E, Laing C, Eklund A, Malm J, Stern C, Rittweger J. Intracranial and intraocular pressure during various degrees of head-down tilt. Aerosp Med Hum Perform. 2017; 88(1):10-16

I n healthy adults on Earth, the balance between intraocular and intracranial pressures (IOP, ICP) results in a small, posteriorly directed gradient across the lamina cribrosa behind the eye. Mechanisms that disrupt homeostasis of the IOP or ICP will alter the translaminar pressure difference (TLPD) and may eventually lead to permanent changes in vision due to alterations in the structural morphology of the posterior eye globe. For example, glaucoma, the second leading cause of blindness worldwide ${ }^{26}$ is primarily associated with an increase in IOP and thus an increased posterior TLPD, leading to progressive degeneration of retinal ganglion cells. In addition, ICP has also been found to be significantly lower in patients with primary open-angle glaucoma and normal-tension glaucoma compared to age-matched controls, demonstrating the importance of taking both ICP and IOP into consideration when evaluating pathologies of the optic nerve head. ${ }^{2}$ On the contrary, a decrease in IOP or increase in ICP can lead to swelling of the optic disc (papilledema), a pathognomonic sign in idiopathic intracranial hypertension (IIH).$^{34}$

Notably, during 6-mo missions onboard the International Space Station (ISS), more than half of astronauts present with structural and functional ophthalmic findings termed the Visual Impairment and Intracranial Pressure (VIIP) syndrome ${ }^{20}$ or Microgravity Ocular Syndrome (MOS). ${ }^{21}$ The syndrome is associated with optic disc swelling, posterior globe flattening, optic nerve sheath distension and choroidal folds, ${ }^{16,20}$ consistent with a reversal of the TLPD in the anterior direction (ICP > IOP) ${ }^{36}$ The etiology of the ocular changes in astronauts is currently unknown; however, our working hypothesis is that exposure to microgravity results in a change in the hydrostatic

From the Institute of Aerospace Medicine, German Aerospace Center (DLR), Cologne, Germany; the Faculty of Medicine, and the Deparment of Pediatrics and Adolescent Medicine, University of Cologne, Cologne, Germany; the Department of Neurology, Baylor College of Medicine, Houston, TX; the Centre for Human and Aerospace Physiological Sciences, King's College London, London, UK; and the Department of Radiation Sciences, the Centre of Biomedical Engineering and Physics, and the Department of Pharmacology and Clinical Neuroscience, Umeå University, Umeå, Sweden.

This manuscript was received for review in April 2016. It was accepted for publication in September 2016

Address correspondence to: Karina Marshall-Goebel, Institute of Aerospace Medicine, Linder Höhe, Cologne, Germany 51147; Karina.Marshall-Bowman@dlr.de.

Reprint \& Copyright $\odot$ by the Aerospace Medical Association, Alexandria, VA. DOI: https://doi.org/10.3357/AMHP.4653.2017 
balance between the IOP and ICP, resulting in a decrease in the TLPD or even shifting in the anterior direction. In addition, ambient carbon dioxide $\left(\mathrm{CO}_{2}\right)$ levels on the ISS are on average 10 times higher than on Earth. ${ }^{17}$ Exposure to elevated ambient $\mathrm{CO}_{2}$, a potent vasodilator, may increase intracranial blood volume via increased cerebral blood flow and, due to the low compliance of the intracranial space, result in an increase in ICP. We also hypothesize that the use of lower body negative pressure (LBNP) may act as a countermeasure by attenuating the headward fluid shift and decrease ICP and IOP by redistributing venous volume to the lower limbs, similarly to the upright position on Earth.

Thus, the primary aim of our study was to evaluate ICP and IOP during various degrees of head-down tilt (HDT, a groundbased spaceflight analog). Our secondary aims were to assess the interacting effects of increased ambient $\mathrm{CO}_{2}$ or LBNP during HDT as exacerbating or attenuating factors on IOP and ICP, respectively.

\section{METHODS}

The study was performed in the :envihab facility at the Institute of Aerospace Medicine, German Aerospace Center in Cologne, Germany. Experiment I was designed to evaluate the effects of various degrees of cephalad fluid shifting during $3.5 \mathrm{~h}$ HDT on cerebral and ocular anatomy and physiology, in addition to investigating the interacting effects of $\mathrm{HDT}$ and $1 \% \mathrm{CO}_{2}$ and $-20 \mathrm{mmHg}$ LBNP. Experiment II was performed to investigate the effects of stronger levels of LBNP $(-40 \mathrm{mmHg})$ for a shorter duration time (5 $\mathrm{min})$ and with an extended range of tilt angles.

\section{Equipment}

ICP was measured with a transcranial Doppler-based noninvasive ICP meter (Vittamed, Kaunas, Lithuania), a device that measures the balance of blood flow pulsations in the intracranial and extracranial ophthalmic artery during six external orbital pressure exposures $(4,8,12,16,20$, and $24 \mathrm{mmHg}) .^{28}$ Two to three ICP measurements were taken at each time point. IOP was measured using an Icare Pro rebound tonometer (Icare, Helsinki, Finland) with three measurements taken in both eyes in a randomized order at each time point. The median value was used for statistical analysis. The intraocular-intracranial pressure difference was calculated by subtracting the ICP from the IOP at each time point. Beat-by-beat mean arterial pressure (MAP) and heart rate (HR) were measured with a Finometer (Finapres Medical Systems, Amsterdam, The Netherlands) on the third phalange of the right hand, leveled to the height of the right atrium. Measurements were taken over $10 \mathrm{~min}$, both at supine baseline and after $3 \mathrm{~h}$ HDT (baseline cardiovascular variables have been reported previously). ${ }^{22}$

All experiments were conducted in accordance with the ethical principles stated in the Declaration of Helsinki and approved by the local ethical commission of the regional medical board (Ärztekammer Nordrhein). All subjects underwent a medical screening prior to inclusion in the studies and written and informed consent was obtained prior to all experiments.

\section{Procedure}

The set-up of Experiment I has been previously described. ${ }^{22}$ Briefly, nine healthy male subjects (mean age \pm SD: $25 \pm 2.4 \mathrm{yr}$; mean body mass index $\pm \mathrm{SD}: 24.1 \pm 2.4 \mathrm{~kg} \cdot \mathrm{m}^{-2}$ ) participated in a crossover design experiment with five randomized conditions: $-6^{\circ},-12^{\circ},-18^{\circ} \mathrm{HDT},-12^{\circ} \mathrm{HDT}$ with $1 \% \mathrm{CO}_{2}$, and $-12^{\circ}$ HDT with $-20 \mathrm{mmHg}$ LBNP, with at least 1 wk between each condition to prevent carry-over effects. Subject exclusion criteria for participation in the study included smoking, current prescription medication use, IOP $>20 \mathrm{mmHg}$, more than +5 or -6 diopters, history of abnormal IOP or diseases of the optic nerve, any neurological or cardiovascular disease, and history of increased ICP. Each experimental day consisted of ICP and IOP baseline data collection in the supine $\left(0^{\circ}\right)$ position, followed immediately by $5 \mathrm{~h}$ total in the HDT position with ICP and IOP measurements taken after $3.5 \mathrm{~h}$ HDT. Increased ambient $\mathrm{CO}_{2}$ was administered with a tank and mask system (tank composition: $1.07-1.09 \% \mathrm{CO}_{2}, 19.7-19.9 \% \mathrm{O}_{2}, \mathrm{~N}_{2}$ balance). A custom designed LBNP was constructed for the $-12^{\circ} \mathrm{HDT}$ position and pressure was maintained at $-20 \mathrm{mmHg}$ in the LBNP chamber throughout the duration of the HDT exposure. Subjects were instructed to consume $40 \mathrm{ml}$ of fluid per kilogram body weight and refrain from caffeinated beverages and alcohol in the $24 \mathrm{~h}$ preceding the experiment. On the experimental day, fluid and nutritional intake was standardized for each individual and kept constant for all five experimental conditions.

Experiment II consisted of 16 healthy subjects (8 male, 8 female; mean age \pm SD: $26.6 \pm 3.7$ yr; mean body mass index \pm SD: $22.7 \pm 2 \mathrm{~kg} \cdot \mathrm{m}^{-2}$ ) that participated in $12 \mathrm{ran}-$ domized conditions: $+12^{\circ}, 0^{\circ},-6^{\circ},-12^{\circ},-18^{\circ},-24^{\circ}$ tilt, and $+12^{\circ}$, $0^{\circ},-6^{\circ},-12^{\circ},-18^{\circ}$, and $-24^{\circ}$ tilt with $-40 \mathrm{mmHg}$ LBNP. Subject exclusion criteria included smoking, current prescription medication use, BMI $>26 \mathrm{~kg} \cdot \mathrm{m}^{-2}$, history of cardiovascular diseases, and severe orthostatic intolerance. During the experiment, subjects remained in the supine $0^{\circ}$ position for a 30 -min baseline prior to tilt exposure. Each subsequent condition was maintained for $5 \mathrm{~min}$, followed by recovery for $10 \mathrm{~min}$ in the supine position before proceeding to the next condition. IOP was measured at baseline $\left(0^{\circ}\right)$, during the last minute of each HDT exposure (i.e., $\min 4$ ), and the last minute of the recovery phase in the supine position (i.e., $\min 9$ ). The experiments were conducted on a custom built, automatic tilt table with an integrated LBNP. The LBNP was sealed at the iliac crest of each subject and ventilation inside the LBNP chamber was maintained during the tilt conditions without LBNP.

\section{Statistical Analysis}

All statistical analyses were carried out with $\mathrm{R}$ version 3.1.2 64-bit (http://www.r-project.org). The level for statistical significance was set to $\alpha=0.05$ and $\beta$ was set to 0.2 . ANOVA and linear mixed effect models with time and condition as main effects and subject ID as a random effect were constructed and Bonferroni posthoc testing was performed. Eye lateralization 
was added as a main effect for IOP analysis. Data are presented as mean \pm SEM for subjects who completed all conditions of the respective study.

\section{RESULTS}

ICP measurements during HDT conditions in Experiment I are shown in Fig. 1. Significant main effects of time $[\mathrm{F}(1,146)=$ 29.7, $P<0.001]$ and condition $[\mathrm{F}(4,146)=7.6, P<0.001]$ were found, with a significant time-condition interaction $[\mathrm{F}(4,146)=6.9, P<0.001]$. Posthoc analysis revealed no change in ICP from the baseline $\left(0^{\circ}\right)$ to $-6^{\circ}(P=0.9)$ or $-12^{\circ}$ HDT $(P=0.4)$, however, there was an increase in ICP from $9.2 \pm 0.9 \mathrm{mmHg}$ at $0^{\circ}$ to $14.4 \pm 1 \mathrm{mmHg}$ during $-18^{\circ} \mathrm{HDT}(P$ $<0.001$, Fig. $1 \mathrm{~A})$. At $-12^{\circ} \mathrm{HDT}$, there was no further change in ICP with the addition of a $1 \% \mathrm{CO}_{2}$ atmosphere $(P=0.7)$ or the addition of $-20 \mathrm{mmHg} \operatorname{LBNP}(P=0.6$, Fig. $1 \mathrm{~B})$.

After $3.5 \mathrm{~h}$ HDT (Experiment I), IOP was found to have significant main effects of time $[(\mathrm{F}(1,158)=132.2, P<0.001]$ and condition $[\mathrm{F}(4,158)=10.97, P<0.001]$ with a significant timecondition interaction $[\mathrm{F}(4,158)=7.4, P<0.001]$. Post hoc analysis revealed that IOP increased from $15.7 \pm 0.3 \mathrm{mmHg}$ at $0^{\circ}$ to $17.9 \pm 0.4 \mathrm{mmHg}$ during $-12^{\circ} \mathrm{HDT}(P<0.001)$ and from $15.3 \pm 0.4 \mathrm{mmHg}$ at $0^{\circ}$ to $18.7 \pm 0.4 \mathrm{mmHg}$ during $-18^{\circ} \mathrm{HDT}$ $(P<0.001$, Fig. 2A). When comparing the HDT conditions, IOP increased from the $-6^{\circ}$ to $-12^{\circ}$ HDT $(P<0.001)$ and further from $-12^{\circ}$ to $-18^{\circ} \mathrm{HDT}(P=0.02)$. During $-12^{\circ} \mathrm{HDT}$ with the addition of $-20 \mathrm{mmHg}$ LBNP, no further change in IOP was detected compared to the $-12^{\circ} \mathrm{HDT}$ plus ambient air pressure condition $(P=0.2$, Fig. $2 \mathrm{~B})$. The addition of $1 \% \mathrm{CO}_{2}$ to $-12^{\circ} \mathrm{HDT}$ resulted in a small decrease in IOP compared to $-12^{\circ}$ HDT plus ambient air $(P<0.001)$, although IOP was still increased compared to baseline $(16.4 \pm 0.4 \mathrm{mmHg}$ vs. $14.8 \pm 0.3 \mathrm{mmHg}$, respectively, $P<0.001$, Fig. $2 \mathrm{~B})$. The posterior intraocular-intracranial pressure difference at supine baseline was maintained during all HDT conditions with no significant main effect of time $[\mathrm{F}(1,67)=0.07, P=0.8]$, however there was a significant main effect of condition $[F(4,67)=$ 3.2, $P=0.02$ ] (Table I).

MAP had a significant main effect of time $[\mathrm{F}(1,79)=34.9$, $P<0.001]$ and increased from $73.6 \pm 2.1 \mathrm{mmHg}$ at $0^{\circ}$ to $89.1 \pm$ $4 \mathrm{mmHg}$ during $-12^{\circ} \mathrm{HDT}+-20 \mathrm{mmHg} \operatorname{LBNP}(P<0.001)$ and
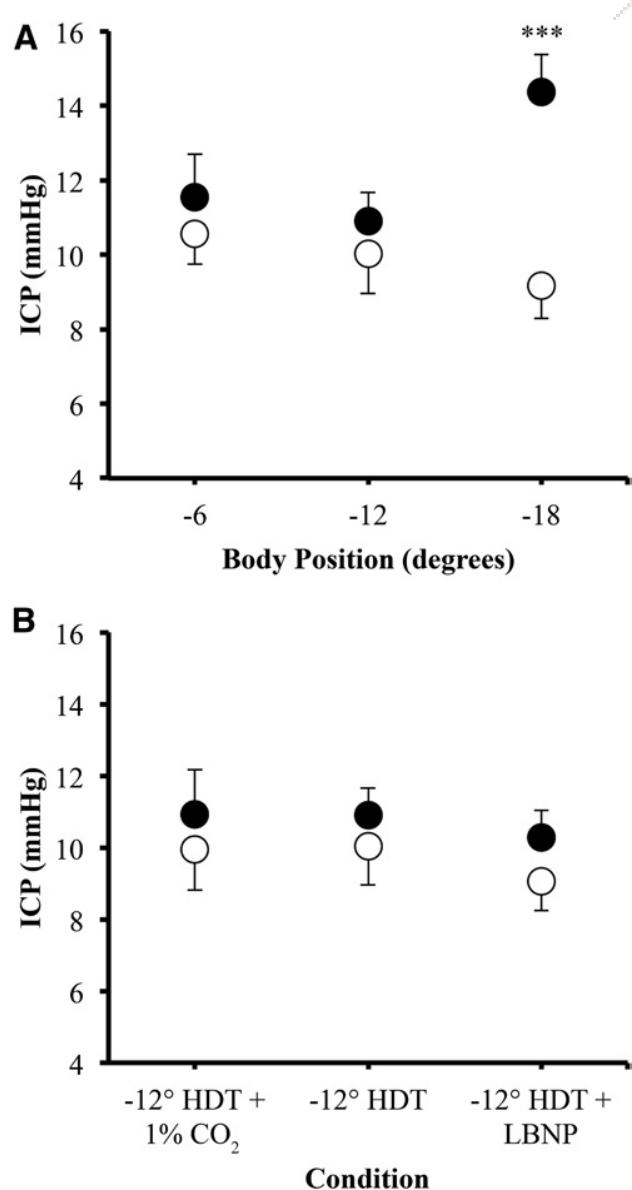

Fig. 1. Intracranial pressure (ICP) before each head-down tilt (HDT) condition at $0^{\circ}$ baseline (white circles) and after $3.5 \mathrm{~h}$ in the HDT position (black circles) during (A) various degrees of $\mathrm{HDT}$ and (B) with the addition of a $1 \% \mathrm{CO}_{2}$ environment and $-20 \mathrm{mmHg}$ lower body negative pressure (LBNP) during $-12^{\circ} \mathrm{HDT}$. Data shown as Mean \pm SEM, ${ }^{* * *} P<0.001$
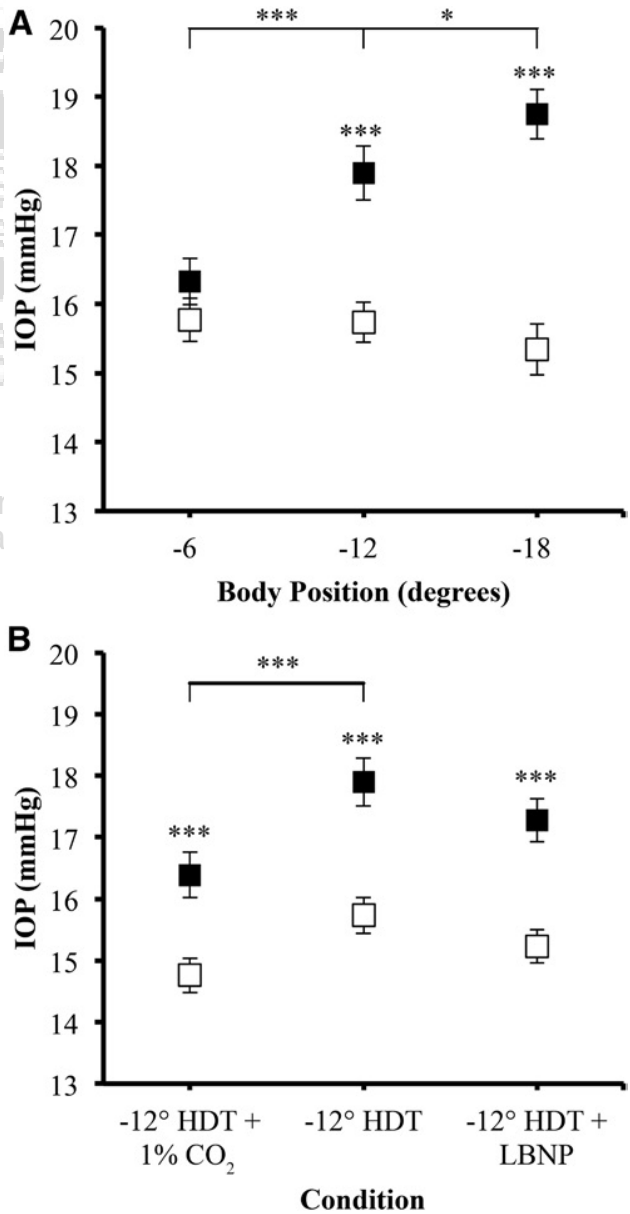

Fig. 2. Intraocular Pressure (IOP) during $0^{\circ}$ baseline (white boxes) and after $3.5 \mathrm{~h}$ in the head-down tilt (HDT) position (black boxes) at (A) various degrees of $\mathrm{HDT}$ and (B) with the addition of a $1 \% \mathrm{CO}_{2}$ environment and $-20 \mathrm{mmHg}$ lower body negative pressure (LBNP). Data shown as Mean $\pm \mathrm{SEM},{ }^{*}=P<$ $0.05, * * * 0<0.001$ 
Table I. The Intraocular-Intracranial Pressure Difference at Baseline $\left(0^{\circ}\right)$ and After 3.5 H Head-Down Tilt (HDT) During Various Conditions.

\begin{tabular}{lrr}
\hline \multirow{2}{*}{ CONDITION } & \multicolumn{2}{c}{$\begin{array}{c}\text { INTRAOCULAR-INTRACRANIAL } \\
\text { PRESSURE DIFFERENCE (mmHg) }\end{array}$} \\
\cline { 2 - 3 } & BASELINE & HDT \\
\hline$-6^{\circ}$ & $4.7 \pm 1.4$ & $4 \pm 1.7$ \\
$-12^{\circ}$ & $6.3 \pm 1.4$ & $7.7 \pm 1.4$ \\
$-12^{\circ}+1 \% \mathrm{CO}_{2}$ & $5 \pm 1.8$ & $4.7 \pm 1.7$ \\
$-12^{\circ}+-20 \mathrm{mmHg}$ LBNP & $6.1 \pm 1.2$ & $7.4 \pm 1.5$ \\
$-18^{\circ}$ & $6 \pm 1.8$ & $4.5 \pm 1.7$ \\
\hline
\end{tabular}

Data shown as Mean $\pm \mathrm{SEM} ; \mathrm{LBNP}=$ lower body negative pressure

also from $71 \pm 2.5 \mathrm{mmHg}$ at $0^{\circ}$ to $84.3 \pm 2.7 \mathrm{mmHg}$ at $-18^{\circ}$ HDT $(P<0.001)$ (Table II). However, condition was not found to be a significant main effect $[\mathrm{F}(4,79)=0.8, P=0.6]$. HR showed a significant main effect of time $[\mathrm{F}(1,79)=9.1, P=$ $0.003]$ but not condition $[\mathrm{F}(4,79)=1.7, P=0.1]$.

In Experiment II, IOP had significant main effects of both time $[\mathrm{F}(1,767)=65.5, P<0.001]$ and condition $[\mathrm{F}(11,767)=$ $17.9, P<0.001]$, with a significant time-condition interaction $[\mathrm{F}(11,767)=21.7, P<0.001]$. IOP increased from an average $0^{\circ}$ baseline of $14.7 \pm 0.1 \mathrm{mmHg}$ to $15.7 \pm 0.4,16.5 \pm 0.3$, and $18.4 \pm 0.4 \mathrm{mmHg}$ during $-12^{\circ},-18^{\circ}$, and $-24^{\circ} \mathrm{HDT}$, respectively $(P=0.02, P<0.001$, and $P<0.001)$ (Fig. 3). The addition of $-40 \mathrm{mmHg}$ LBNP during HDT was able to attenuate HDTinduced increases in IOP during $-12^{\circ}$ and $-18^{\circ} \mathrm{HDT}$, however at $-24^{\circ}$ HDT, IOP was increased above baseline values ( $16 \pm 0.3$ $\mathrm{mmHg}$ vs. $14.6 \pm 0.3 \mathrm{mmHg}$, respectively $P<0.001$ ). In both experiments, there was a trend toward significance for eye lateralization as a main effect $[\mathrm{F}(1,158)=3.6, P=0.06$, and $\mathrm{F}(1,767)$ $=5.1, P=0.05$ for Experiment I and II, respectively].

\section{DISCUSSION}

Overall, we found that IOP and ICP increase with steeper HDT angles, although in a divergent way. Further, IOP always remained higher than ICP, thus maintaining a posterior intraocularintracranial pressure difference across all HDT angles. The addition of a $1 \% \mathrm{CO}_{2}$ atmosphere or low level LBNP $(-20 \mathrm{mmHg})$ in the $-12^{\circ} \mathrm{HDT}$ position for $3.5 \mathrm{~h}$ did not significantly affect IOP or ICP compared to HDT alone. However, increases in IOP from baseline were attenuated with stronger LBNP $(-40 \mathrm{mmHg})$ during short-duration HDT exposure.

On Earth, IIH is characterized by elevated ICP ${ }^{9}$ resulting in a decrease or even reversal of the TLPD in the anterior

Table II. Mean Arterial Pressure (MAP) and Heart Rate (HR) at Baseline $\left(0^{\circ}\right)$ and After $3.5 \mathrm{~h}$ Head-Down Tilt (HDT) During Various Conditions.

\begin{tabular}{llllll}
\hline & \multicolumn{2}{c}{ MAP $(\mathbf{m m H g})$} & & \multicolumn{2}{c}{ HR (bpm) } \\
\cline { 2 - 3 } CONDITION & BASELINE & \multicolumn{1}{c}{ HDT } & & BASELINE & \multicolumn{1}{c}{ HDT } \\
\hline$-6^{\circ}$ & $73.2 \pm 3.6$ & $82.0 \pm 5.1$ & & $61.9 \pm 3.2$ & $60 \pm 2.6$ \\
$-12^{\circ}$ & $75.3 \pm 4.1$ & $81.8 \pm 5.1$ & & $65.1 \pm 2.7$ & $60.6 \pm 3.2$ \\
$-12^{\circ}+1 \% \mathrm{CO}_{2}$ & $76.9 \pm 4$ & $81.4 \pm 2.6$ & & $60.1 \pm 3.2$ & $55.7 \pm 3.1$ \\
$-12^{\circ}+-20 \mathrm{mmHg}$ & $73.6 \pm 2.1$ & $89.1 \pm 4^{* * *}$ & & $61.9 \pm 3.6$ & $59.4 \pm 4$ \\
$\quad$ LBNP & & & & & \\
$-18^{\circ}$ & $71 \pm 2.5$ & $84.3 \pm 2.7^{* * *}$ & & $59.8 \pm 2.9$ & $59 \pm 2$ \\
\hline
\end{tabular}

Data shown as Mean \pm SEM; LBNP = lower body negative pressure; ${ }^{* *} P<0.001$

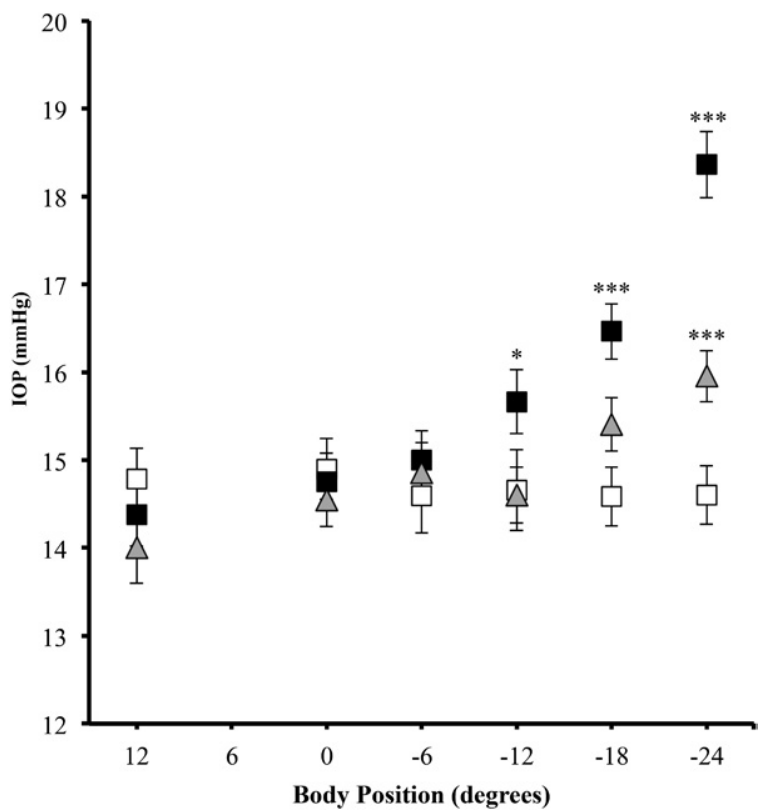

Fig. 3. Intraocular Pressure (IOP) at $0^{\circ}$ baseline (white boxes), after 5 min headdown tilt (HDT, black boxes) and after 5 min HDT with -40 mmHg lower body negative pressure (LBNP, gray triangles). Data shown as Mean $\pm \mathrm{SEM}^{*}{ }^{*}=P<$ $0.05, * * * P<0.001$

direction accompanied by papilledema due to disruption of axonal transport in the optic nerve and subsequent visual impairment. Similar ophthalmic findings are also seen in astronauts on long-duration missions aboard the ISS, ${ }^{16,20}$ prompting the hypothesis that these changes arise from an anterior TLPD due to either an increase in ICP and/or a decrease in IOP. However, contrary to IIH which primarily affects obese women of child bearing age ${ }^{34}$, astronauts do not present with many of the common IIH symptoms including severe chronic headache, pulse synchronous tinnitus, and diplopia. Furthermore, a posterior intraocular-intracranial pressure difference was maintained during simulated microgravity (HDT). Taken together, the differences between IIH and the VIIP syndrome suggest an etiology unique to the microgravity environment due to the loss of all hydrostatic gradients. However, the two pathologies both present with signs consistent with a lack of ICP 'unloading' in the upright position due to either an abnormally increased ICP in the upright position (IIH) or a lack of upright position all together (VIIP).

In addition, it is important to note that the pressure gradient across the lamina cribrosa cannot be simplified to only equal the difference between IOP and ICP, but rather biomechanical and material properties of tissues of the eye and optic nerve need to be considered as well. A modeling study by Feola et al. found that along with ICP and IOP, optic nerve and lamina cribrosa stiffness had significant effects on optic nerve head strains. ${ }^{12}$ Moreover, the thickness of the lamina cribrosa affects the translaminar pressure gradient with a thicker lamina cribrosa spreading the gradient over a greater distance and reducing the shear stress. ${ }^{24}$ Thus, individual anatomical differences may help explain the variance in severity of ocular changes in astronauts, as a small increase in ICP and/or decrease in IOP will result 
in an amplified the translaminar pressure gradient across a thinner lamina cribrosa.

According to Davson's equation, ICP is highly dependent on the cerebral venous pressure. ${ }^{8,27}$ In a fully communicating venous system, venous pressure is subject to hydrostatic pressure gradients referenced to the hydrostatic indifference point (HIP), a point in the venous system where venous pressure is unchanged regardless of body position, located at the apex of the diaphragm. Petersen et al. found ICP to increase 4.9 and $9.6 \mathrm{mmHg}$ during $-10^{\circ}$ and $-20^{\circ} \mathrm{HDT}$, respectively, in neurosurgical patients after 5 min HDT compared to the supine baseline. ${ }^{25}$ In the present study, ICP was found to increase about $5 \mathrm{mmHg}$ during $3.5 \mathrm{~h}$ exposure to $-18^{\circ} \mathrm{HDT}$ compared to the supine baseline, a smaller increase than predicted by hydrostatic pressure from the HIP alone. However, the noninvasive TCD-based ICP measurement may underestimate ICP compared to invasive measurements, especially at higher ICP levels. ${ }^{15}$ Additional validation studies have found the TCDbased noninvasive ICP meter to have good correlation with invasive ICP measures, ${ }^{28}$ with a mean difference between paired measures of about $4.5 \mathrm{mmHg}$. ${ }^{3}$ Therefore, it is possible that in the present study, ICP was slightly elevated in the $-6^{\circ}$ and $-12^{\circ}$ HDT positions but was too small to be detected by noninvasive measures.

On the contrary, all hydrostatic gradients are abolished in real microgravity and a headward fluid shift of approximately 1-2 1 occurs with notable facial puffiness ${ }^{14}$ and decreased leg volume. ${ }^{23}$ This fluid shift may lead to decreased cerebral venous outflow and increased cerebral venous pressure, potentially exacerbated by anatomical compression of the internal jugular veins which may not occur during HDT. ${ }^{35}$ A recent parabolic flight study involving patients with existing access to the CSF space via Ommaya reservoir found ICP to increase during the microgravity portion of the flight compared to the seated upright position (13 vs. $4 \mathrm{mmHg}$, respectively), although decrease compared to the supine position $(15 \mathrm{mmHg}) \cdot{ }^{18} \mathrm{Dur}-$ ing a 9-d spaceflight, ICP was measured directly in a primate onboard the Russian biosatellite Cosmos-2229, and was found to increase initially by $25-30 \%$ compared to seated baseline preflight, and decreased over the second half of the mission close to baseline values, although still slightly elevated. ${ }^{33}$ However, central venous pressure measured in humans in the first hours of microgravity exposure, did not increase but rather decreased below seated baseline values, likely due to gravitational unloading and subsequent expansion of the thorax. ${ }^{6}$ On Earth, the large, and likely gravity dependent change in ICP when going from the upright position to supine (about $\left.12-13 \mathrm{mmHg},{ }^{25,27}\right)$ is much greater than the change in IOP (about $\left.2-3 \mathrm{mmHg},{ }^{1,19}\right)$, demonstrating that a large TLPD $(\sim 20$ $\mathrm{mmHg}^{11}$ ) exists two-thirds of the day when a person is upright whereas during sleep, the TLPD is greatly reduced (although still in the posterior direction). In microgravity, however, the loss of all hydrostatic pressure gradients may result in a constant difference between IOP and ICP over $24 \mathrm{~h}$, hypothesized to be similar to the corresponding pressure difference in the supine or HDT position on Earth ( 5-7 mmHg), resulting in a reduction of the TLPD and possibly shifting to the anterior direction. Further investigation of gravity and posture-dependence of both ICP and IOP should be performed when considering the etiology of the vision changes during spaceflight.

According to the Goldmann equation, ${ }^{5} \mathrm{IOP}$ is dependent on the episcleral venous pressure (EVP), as any rise in EVP will increase the resistance to aqueous humor outflow. When going from the seated to supine position, EVP increases by about $1 \mathrm{mmHg},{ }^{30}$ and is hypothesized to increase further during HDT due to increased cerebral venous pressure. Combined with engorgement of the choroid, IOP increases with progressive HDT angles as demonstrated. A number of studies have demonstrated that IOP increases immediately upon exposure to both real and simulated microgravity. ${ }^{31}$ However, sustained bed rest studies have shown variable results. Chiquet et al. ${ }^{7}$ found that after $5-6 \mathrm{~d}$ of $-6^{\circ}$ HDT bed rest, IOP normalizes or even goes below supine baseline values, whereas Taibbi et al. ${ }^{32}$ found a $\sim 2 \mathrm{mmHg}$ increase in IOP after $10 \mathrm{~d}$ of $-6^{\circ}$ HDT bed rest. In space, evidence suggests that IOP returns to baseline values within the first week of microgravity exposure. ${ }^{10,29}$ It is therefore possible that an abnormally low baseline IOP may be a factor in the development of ophthalmic abnormalities in space due to a lower baseline TLPD. It is also interesting to note that structural ophthalmic changes in astronauts appear to affect the right eye more than the left, ${ }^{20}$ whereas asymmetric papilledema in patients with IIH on Earth is fairly uncommon. ${ }^{4}$ The present study found a trend toward a difference in IOP between the left and right eye and further studies are warranted to elucidate the potential pathophysiologic role of bilateral variations in IOP, the bony optic canal and the vascular system in the VIIP syndrome.

The addition of increased ambient $\mathrm{CO}_{2}$ during HDT bed rest represents a more realistic analog of the ISS environment as the partial pressure of $\mathrm{CO}_{2}$ on the space station ranges from 2.3 to $5.3 \mathrm{mmHg}(0.1-0.8 \%)$ compared to the normal $0.3 \mathrm{mmHg}(0.04 \%)$ on Earth. ${ }^{17}$ In the present study, we found IOP to decrease slightly during $-12^{\circ} \mathrm{HDT}$ plus $1 \% \mathrm{CO}_{2}$ compared to $-12^{\circ} \mathrm{HDT}$ alone, however, the absolute increases from their respective baselines were similar $(1.8$ and $2.2 \mathrm{mmHg}$, respectively). Furthermore, the added $1 \% \mathrm{CO}_{2}$ environment had no detectable effects on ICP during HDT, although was shown previously to alter cerebral hemodynamics. ${ }^{22}$ The lack of effects seen on ICP and IOP may be due to the relatively low $\mathrm{CO}_{2}$ exposure level in the present study and therefore only a very small increase in end tidal $\mathrm{CO}_{2}{ }^{22}$

While increased ambient $\mathrm{CO}_{2}$ was hypothesized to be a negative influencing factor, LBNP was tested as a potential countermeasure to HDT cephalad fluid shifting. Normally, LBNP is implemented as a tool to evoke an orthostatic challenge, for instance to study orthostatic intolerance, and the majority of research studies performed with LBNP are done at levels between -40 and $-50 \mathrm{mmHg} .{ }^{13}$ In the present study, $-40 \mathrm{mmHg}$ LBNP was able to attenuate HDT-induced increases in IOP up to $-18^{\circ} \mathrm{HDT}$, likely by counteracting the HDT-induced cephalad fluid shift and redistributing venous blood to the lower limbs. 
In order to determine the feasibility of implementing LBNP for use as a potential countermeasure, we implemented low level $(-20 \mathrm{mmHg}) \mathrm{LBNP}$ during $-12^{\circ} \mathrm{HDT}$ for $5 \mathrm{~h}$ total. At this LBNP level, subjects were able to tolerate the countermeasure with reasonable comfort, although IOP remained increased from the supine baseline after $3.5 \mathrm{~h}$. However, Macias et al. demonstrated that during $-15^{\circ} \mathrm{HDT}, 10$-min exposure to $-25 \mathrm{mmHg}$ LBNP normalized IOP to supine baseline values, although still elevated compare to seated baseline levels. ${ }^{19}$ Therefore, low level LBNP (-20 mmHg) may not be able to sustain changes in IOP over longer-duration exposure. Furthermore, $-40 \mathrm{mmHg} \mathrm{LBNP}$ was found to significantly reduce IOP during HDT, however, further studies are warranted to determine the effects of strong LBNP on ICP and the TLPD.

There are several limitations inherent to the presented studies. First, the performed studies demonstrate a simulation of spaceflight, however, in an Earth-based model such as bed rest, $a G_{z}$ gravitational gradient still exists which is not present in space and therefore, extrapolation of findings from HDT to real microgravity warrant caution. In addition, the baseline measurements were taken in supine position; however, as humans spend approximately two-thirds of their day in the upright position, it would be useful for future studies to compare interventions to both upright and supine postures. Furthermore, additional studies are necessary to determine the long-duration effects of real and simulated microgravity on both ICP and IOP, as ocular changes in astronauts are not an immediate effect of spaceflight but rather arise after weeks or months living in microgravity. It is, therefore, likely that the ophthalmic changes in astronauts occur after an acclimatization of the human body to the microgravity environment and soft tissue remodeling due to newly developed tissue stresses and strains.

Overall, this study is the first to report changes in both IOP and ICP during exposure to various degrees of HDT. The results of this ground-based spaceflight analog study demonstrate that a small, yet sustained posterior intraocular-intracranial pressure difference is maintained during HDT, and is not altered in the presence of increased ambient $\mathrm{CO}_{2}$. The lack of a larger intraocular-intracranial pressure difference during HDT, normally present in the upright position on Earth, may be responsible for the structural and functional ophthalmic changes seen in association with the VIIP syndrome due to a lack of diurnal posture-dependent changes in the TLPD. Furthermore, long exposure to $-20 \mathrm{mmHg}$ LBNP has no effects on ICP or IOP, however $-40 \mathrm{mmHg}$ LBNP for short durations was able to attenuate HDT-induced increases in IOP. Further studies are warranted to determine the effects of higher level LBNP on ICP and feasible pressure levels to have positive effects yet remain operationally feasible.

\section{ACKNOWLEDGMENTS}

The authors would like to thank Dr. Krassimira Ivanova for her significant professional contributions to editing the manuscript, Dr. Bernd Johannes for his statistical consultation and Arminas Ragauskas and Rolandas Zakelis for providing training and technical support during the study.
K. Marshall-Goebel received a Helmholtz Space Life Sciences Research School (SpaceLife) Ph.D. scholarship, funded in equal parts by the Helmholtz Association (grant no. VH-KO-300) and the German Aerospace Center (DLR).

Authors and affiliations: Karina Marshall-Goebel, M.Sc., B.A., Edwin Mulder, Ph.D., M.Sc., Charles Laing, M.Sc., B.Sc., Claudia Stern, M.D., and Jörn Rittweger, M.D., Institute of Aerospace Medicine, German Aerospace Center (DLR), Cologne, Germany; Eric Bershad, M.D., Department of Neurology, Baylor College of Medicine, Houston, TX; and Anders Eklund, Ph.D., Department of Radiation Sciences, and Jan Malm, M.D., Ph.D., Department of Pharmacology and Clinical Neuroscience, Umeå University, Umeå, Sweden;

\section{REFFERENCES}

1. Anderson AP, Swan JG, Phillips SD, Knaus DA, Kattamis NT, et al. Acute effects of changes to the gravitational vector on the eye. J Appl Physiol. 2016; 120:939-946

2. Berdahl JP, Fautsch MP, Stinnett SS, Allingham RR. Intracranial pressure in primary open angle glaucoma, normal tension glaucoma, and ocular hypertension: a case-control study. Invest Ophthalmol Vis Sci. 2008 49:5412-5418

3. Bershad EM, Anand A, DeSantis SM, Yang M, Tang RA, et al. Clinical validation of a transcranial doppler-based noninvasive intracranial pressure meter: a prospective cross-sectional study. World Neurosurg. 2016; 89:647-653.e1

4. Bidot S, Bruce BB, Saindane AM, Newman NJ, Biousse V. Asymmetric papilledema in idiopathic intracranial hypertension. J Neuroophthalmol. 2015; 35:31-36.

5. Brubaker RF. Goldmann's equation and clinical measures of aqueous dynamics. Exp Eye Res. 2004; 78:633-637.

6. Buckey JC, Gaffney FA, Lane LD, Levine BD, Watenpaugh DE, et al. Central venous pressure in space. J Appl Physiol. 1996; 81:19-25.

7. Chiquet C, Custaud M-A, Le Traon AP, Millet C, Gharib C, Denis P. Changes in intraocular pressure during prolonged (7-day) head-down tilt bedrest. J Glaucoma. 2003; 12:204-208.

8. Davson H, Hollingsworth G, Segal MB. The mechanism of drainage of the cerebrospinal fluid. Brain. 1970; 93:665-678.

9. Degnan AJ, Levy LM. Pseudotumor cerebri: brief review of clinical syndrome and imaging findings. AJNR Am J Neuroradiol. 2011; 32: 1986-1993.

10. Draeger J, Schwartz R, Groenhoff S, Stern C. [Self tonometry during the German 1993 Spacelab D2 mission]. Ophthalmologe. 1994; 91:697-699 (Ger).

11. Eklund A, Jóhannesson G, Johansson E, Holmlund P, Qvarlander S, et al. The pressure difference between eye and brain changes with posture. Ann Neurol. 2016; 80:269-276.

12. Feola AJ, Myers JG, Raykin J, Mulugeta L, Nelson ES, et al. Finite element modeling of factors influencing optic nerve head deformation due to intracranial pressure. Invest Opthalmol Vis Sci. 2016; 57:1901-1911.

13. Goswami N, Loeppky JA, Hinghofer-Szalkay H. LBNP: past protocols and technical considerations for experimental design. Aviat Space Environ Med. 2008; 79:459-471.

14. Kirsch KA, Baartz FJ, Gunga HC, Röcker L. Fluid shifts into and out of superficial tissues under microgravity and terrestrial conditions. Clin Investig. 1993; 71:687-689.

15. Koskinen LD, Malm J, Zakelis R, Bartusis L, Ragauskas A, Eklund A Can intracranial pressure be measured non-invasively bedside using a two-depth Doppler-technique? J Clin Monit Comput. 2016; doi:10.1007/ s10877-016-9862-4.

16. Kramer LA, Sargsyan AE, Hasan KM, Polk JD, Hamilton DR. Orbital and Intracranial Effects of Microgravity: Findings at 3-T MR Imaging. Radiology. 2012; 263:819-27.

17. Law J, Van Baalen M, Foy M, Mason SS, Mendez C, et al. Relationship between carbon dioxide levels and reported headaches on the international space station. J Occup Environ Med. 2014; 56:477-83. 
18. Lawley J, Williams M, Petersen L, Zhang R, Whitworth T, Levine B. ICP During Daily Life in Healthy Adults: What Does Microgravity Add to the Mix? FASEB J 2015; 29:990.10.

19. Macias BR, Liu JHK, Grande-Gutierrez N, Hargens AR. Intraocular and intracranial pressures during head-down tilt with lower body negative pressure. Aerosp Med Hum Perform. 2015; 86:3-7.

20. Mader TH, Gibson CR, Pass AF, Kramer LA, Lee AG, et al. Optic disc edema, globe flattening, choroidal folds, and hyperopic shifts observed in astronauts after long-duration space flight. Ophthalmology. 2011; 118:2058-69.

21. Marshall-Bowman K, Barratt MR, Gibson CR. Ophthalmic changes and increased intracranial pressure associated with long duration spaceflight: an emerging understanding. Acta Astronaut. 2013; 87:77-87.

22. Marshall-Goebel K, Ambarki K, Eklund A, Malm J, Mulder E, et al. Effects of short-term exposure to head-down tilt on cerebral hemodynamics: a prospective evaluation of a spaceflight analog using phase-contrast MRI. J Appl Physiol. 2016; 120:1466-73.

23. Moore TP, Thornton WE. Space shuttle inflight and postflight fluid shifts measured by leg volume changes. Aviat Space Environ Med. 1987; 58:A91-A96.

24. Morgan WH, Balaratnasingam C, Lind CRP, Colley S, Kang MH, et al. Cerebrospinal fluid pressure and the eye. Br J Ophthalmol. 2016; 100 71-77.

25. Petersen LG, Petersen JCG, Andresen M, Secher NH, Juhler M. Postural influence on intracranial and cerebral perfusion pressure in ambulatory neurosurgical patients. Am J Physiol Regul Integr Comp Physiol. 2016; 310:R100-R104.

26. Quigley HA, Broman AT. The number of people with glaucoma worldwide in 2010 and 2020. Br J Ophthalmol. 2006; 90:262-267.
27. Qvarlander S, Sundström N, Malm J, Eklund A. Postural effects on intracranial pressure: modeling and clinical evaluation. J Appl Physiol. 2013; 115:1474-1480.

28. Ragauskas A, Bartusis L, Piper I, Zakelis R, Matijosaitis V, et al. Improved diagnostic value of a TCD-based non-invasive ICP measurement method compared with the sonographic ONSD method for detecting elevated intracranial pressure. Neurol Res. 2014; 36:607-614.

29. Schwartz R, Draeger J, Groenhoff S, Flade KD. [Results of self-tonometry during the 1st German-Russian MIR mission 1992]. Ophthalmologe 1993; 90:640-642 (Ger).

30. Sultan M, Blondeau P. Episcleral venous pressure in younger and older subjects in the sitting and supine positions. J Glaucoma. 2003; 12:370-373.

31. Taibbi G, Cromwell RL, Kapoor KG, Godley BF, Vizzeri G. The effect of microgravity on ocular structures and visual function: a review. Surv Ophthalmol. 2013; 58:155-163.

32. Taibbi G, Cromwell RL, Zanello SB, Yarbough PO, Ploutz-Snyder RJ, et al. Ocular outcomes evaluation in a 14-day head-down bed rest study. Aviat Space Environ Med. 2014; 85:983-992.

33. Trambovetskii EV, Krotov VP, Korol'kov VI. [Intracranial pressure in monkeys during the flight of Cosmos-2229]. Aviakosm Ekolog Med. 1995; 29:37-41 (Rus).

34. Wall M. Idiopathic intracranial hypertension. Neurol Clin. 2010; 28 593-617.

35. Wiener TC. Space obstructive syndrome: intracranial hypertension, intraocular pressure, and papilledema in space. Aviat Space Environ Med. 2012; 83:64-66.

36. Zhang L-F, Hargens AR. Intraocular/intracranial pressure mismatch hypothesis for visual impairment syndrome in space. Aviat Space Environ Med. 2014; 85:78-80.

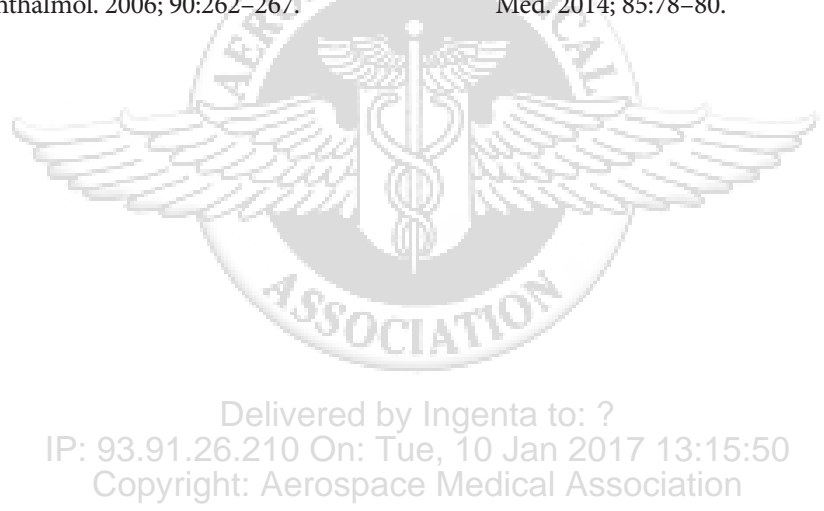

